\title{
Sub Clinical Mastitis in Dairy Farms of Addis Ababa and Sebeta Towns, Ethiopia
}

\author{
Belay Geleta1, Desta Beyene ${ }^{1}$, Alehegn Wubete $^{2}$ and Fufa Abunna*3 \\ ${ }^{1}$ Haramaya University, College of Veterinary Medicine, Ethiopia \\ ${ }^{2}$ National Animal Health Research and Disease Investigation Center, Ethiopia \\ ${ }^{3}$ Addis Ababa University, Department of Clinical Studies, Ethiopia
}

Received: 悳: December 27, 2018; Published: 眥: January 09, 2019

*Corresponding author: Fufa Abunna, College of Veterinary Medicine and Agriculture, Department of Clinical Studies, Haramaya University, P.O. Box 34, Bishoftu, Oromia, Ethiopia

\begin{abstract}
A cross- sectional study was carried out from October 2010 to March 2011 to estimate prevalence of subclinical mastitis and to see associated risk factors in lactating dairy cows in Addis Ababa and Sebeta towns. All dairy cows were apparently healthy with clinically sound udder secreting apparently normal milk. All the cows lived nearly under the same conditions of breeding from the habitat, hygiene and feeding systems. Quarter milk samples were collected from the milking cows and screened for mastitis using the California Mastitis Test (CMT). Based on CMT of the 384 cows examined, 300 (78.13\%) had subclinical mastitis. Among the 1536 quarters examined, 730 (47.52\%) were CMT positive and 110 (7.16\%) blind. Of the study farm, farm F has got the highest prevalence (58.87\%) and the lowest was at farm D (36.96\%). The prevalence of CMT-positive cows was $47.52 \%$, all of which had sub-clinical mastitis.

Among 384 cows tested, 170 of them belonged to the age group of 2 to 4 years and 126 cows (74.12\%) had 290 infected quarters (42.64\%), whereas 185 of them belonged to the age group of 4-8 years, which 150 cows (81.08\%) had 378 infected quarters (63\%), and 29 of them belonged to the age groups of greater than 8 years, which 24 cows $(82.75 \%)$ had 62 infected quarters (53.44\%). Stage of lactation and parity affect mastitis prevalence significantly $(\mathrm{p}<0.05)$. Cows with many calves $(>6)$ were at the highest risk $(100 \%)$ than those with fewer $(3)$ calves $(82.95 \%)$ and moderate (3-6) calves (67.47\%). Subclinical mastitis prevalence was higher in late lactation (80.65 \%) and lower in early lactation (70.54\%) and highest in mid lactation (83.21\%). It was found that 177 out of 1536 quarters (11.52\%) showed higher degree (+++), 238 ones (15.49\%) showed moderate degree (++), 315 ones (20.51\%) lower degree (+) and the rest $696(45.32 \%)$ were negative (-). The obtained results provided the importance of CMT for diagnosis of subclinical mastitis as it is a reliable, easy, rapid and cheap tool helping in diagnosis and controlling the disease because it directs attention to individual mammary quarter that is secreting milk of high somatic cell content.
\end{abstract}

Keywords: CMT; Prevalence; Subclinical Mastitis; Crossbred; Sebeta; Addis Ababa

\section{Introduction}

Dairy production is a biologically efficient system that converts feed and roughages to milk [1]. Milk is a very nutritional food that is rich in carbohydrate, proteins, fats, vitamins and minerals, and is one of the most important foods of human beings. Bovine mastitis is a single most common disease syndrome in adult dairy cows, accounting for about $38 \%$ of morbidity [2]. Mastitis in both clinical and subclinical forms is frustrating, costly and extremely complex disease that results in a marked reduction in the quality and quantity of milk [3]. Mastitis is often the result of the interaction of several factors such as man, cow, environment, microorganisms and management [4]. Mastitis can occur in either clinical or subclinical forms; clinical mastitis is characterized by changes in the udder and milk that are directly observable, whereas the subclinical mastitis disease is characterized by an increase in somatic cells in the milk, and the absence of clinical signs. In East Africa, the prevalence of subclinical mastitis, as defined by the CMT, has been reported to range from 47 to 90 percent of cows, and 28 to 33 percent of quarters [5-7].

According to [8] of the major diseases of crossbred cows in Addis Ababa milk shed; mastitis was the second most frequent disease next to reproductive diseases. In most studies most of the cases of mastitis were subclinical compared to clinical mastitis. 
Previous study on the prevalence of mastitis indicated $10 \%$ of cows in most farms in Ethiopia have at least one blind quarter. The prevalence of bovine mastitis is higher in farms with larger herd sizes than in those with lower herd sizes. The prevalence of clinical and sub clinical mastitis in Ethiopia range from 1.2 to $21.5 \%$ and 19 to $46.6 \%$, respectively [8-10]. According to [11] losses associated with subclinical mastitis (SCM) in crossbred dairy cows in the central highlands of Ethiopia was found to be US\$38 for each cow per lactation. This is due to decrease production, treatment cost, increased labor, milk withheld following treatment and premature culling [12].

In Ethiopia, the subclinical form of mastitis received little attention and efforts have been concentrated on the treatment of clinical cases. Ethiopian dairy farm owners, especially smallholders, were unaware of the invisible loss from subclinical mastitis and were also true in Tanzanian and Ugandan farmers [7,13]. In this study too all the attendants practice hand milking and their knowledge about mastitis were only on clinical mastitis; none of them were known about subclinical mastitis. The most common causative organisms of udder disease include: Staphylococci (S. aureus and Staph. epidermidis), Streptococci (Str. agalactiae, Str. dysgalactiae, Str. uberis and Str. bovis) and coliforms (mainly E. coli and Klebsiella pneumoniae). Among all the pathogens of bovine mastitis, S. aureus is the predominant organism [14]. There are many factors responsible for the mammary glands' infection, (e.g. hygiene, housing, climate, milking machines, feed, genetics), acting simultaneously. A typical scenario that leads to mastitis infection are: contact with the microbes, entry of microbes into the teats and immune response of the animal.

It is even more difficult to generalize about the relative importance of each one, as certain factors affect certain microorganisms. Climate may have a direct or indirect influence on the onset of mastitis. Biting insects, excessive humidity, stress, temperature extremes, bedding condition, muddy conditions caused by abundant rainfall will increase the number of microorganisms and thus increase risks of infection. The different dairy cattle breeds are not equally susceptible to mastitis. High yielding cows are more likely to be affected. Selective breeding that focuses solely on milk production is undoubtedly an important factor in higher rates of mastitis. According to different sources, hereditary factors account for $12 \%$ to $20 \%$ of susceptibility to mastitis in a single breed [15]. This study was, therefore, primarily conducted to determine the prevalence of subclinical mastitis and to assess the major risk factors associated with the occurrence of the disease in Addis Ababa city and Sebeta town.

\section{Materials and Methods}

\section{Study Area}

The study was conducted in Addis Ababa and Sebeta towns. The cattle population of Addis Ababa and Sebeta is 90,000 and 105,355 respectively. Addis Ababa and Sebeta located at 901'48" N latitude and 38044'24" E longitude with an average altitude of 2400 meter, and $25 \mathrm{~km}$ south west of Addis Ababa at altitude of 8055'N38037'E and longitude of 8.9170 N38.6170E and elevation of 2,356 m.a.s.l., respectively. Addis Ababa has an average annual rainfall of 50 inches and $62.9^{\circ} \mathrm{F}$ temperatures while Sebeta has an average annual rainfall of 866-1200 millimeters and $180 \mathrm{C}-250 \mathrm{C}$ temperature. Addis Ababa has two primary seasons: a dry season from October to February, and for the rest of the year, a rainy season, divided into "small rains" and "big rains." The small rains, February through April. The big rains, June through September and has an average rainfall of $91 \mathrm{~mm}$ per month with $60.1 \%$ annual relative humidity which ranges from $49 \%$ in February to $82 \%$ in July [16-17].

\section{Study Animals and Husbandry}

The study animals were lactating Holstein X Zebu cross bred dairy cows in Addis Ababa and Sebeta towns' dairy farms. The study was conducted in large dairy farms containing a herd size of 50 and above dairy cows and each dairy farm would have an average of 45 lactating dairy cows. All dairy farms are managed under intensive management systems and they are often provided with some supplementary diet in addition to the natural pasture and agricultural byproducts such as molasses, silage and brewery byproducts. Although milking is done by hand, pre-milking and post-milking hygienic procedures, such as udder washing and drying, were frequently practiced using common towel for all cows. Cows can dry off at late-lactation period by abrupt cessation of milking. Floors are made up of concrete but none of them use bedding. Even though the floors are cemented/hard, smooth, not keep dry, and the dung and urine are not removed immediately. The average daily milk production from individual cow was ranges from 1 to 27 liter per day.

\section{Study Design}

Sample Size Determination and Sampling Strategy: The study was a cross-sectional study conducted on dairy cow farms from October 2010 to May 2011 in Addis Ababa and Sebeta towns at cow and quarter level based on California Mastitis Test (CMT). Prevalence was calculated according to the formula given by [18]. Sample size is determined at $95 \%$ confidence level, $5 \%$ precision and $50 \%$ expected prevalence and found to be 384 dairy cows. All the dairy farms were taken from urban agriculture offices to use them as sampling frame and, therefore, nine dairy farms were selected based on simple random sampling techniques. Age of the animal was determined from birth records and dentition characteristics and categorized as young adults (2-4 years), adult (4-8years) and old (>8years). Stage of lactation was categorized as early (up to 3 months), mid (3rd to 7th month) and late (7th month to beginning of dry period). Parity was categorized as few (1-3 calves), moderate ( 4 - 6 calves) and many (> 6 calves) [8].

Sample Collection and CMT Tests: The udder, especially the teats, were cleaned and dried before milk sample collection. Dust, particles of bedding and other filth were removed by brushing the surface of the teats and udder with a dry towel. The teats were washed with tap water and dried. To prevent recontamination of teats during scrubbing, teats on the far side of the udder were scrubbed with $70 \%$ ethyl alcohol first, then those on the near side 
[19]. After removing the first and second squirt of milk, about $2 \mathrm{ml}$ of milk from each quarter was placed in each four shallow cups in CMT paddle. And then an equal amount of the CMT reagent was added to each cup. A gentle circular motion was applied to the mixtures in a horizontal plane for 15 seconds. A cow or a quarter was considered to have subclinical mastitis if CMT score is 1,2 or 3 and the CMT test was carried out according to the method described by [20].

Data Analysis: Prevalence of mastitis related to specific risk factors was determined as the proportion of affected cows out of the total examined. The collected specific data (body condition, age, parity, lactation stage, and site) were entered to Microsoft Excel spread sheet and analyzed by using STATA 11.0 software version. $\mathrm{p}<0.05$ was significantly different where risk factors were compared to the prevalence.

\section{Results}

Generally, the house condition was similar and satisfactory. Concerning hygienic status in the dairy farms in the study site, one owner did not clean the udder rather stimulate by palpation and wash their hands before and after milking. The floor condition of farm $\mathrm{F}$ is not having suitable drainage and remains moist. The farming system in dairy was mainly characterized by predominantly zero grazing (100\%). Out of 1536 quarter (384 cows) examined,
$730(47.52 \%)$ had subclinical mastitis and 110 were blind (7.16\%) (Table1). Among the study areas farm $\mathrm{F}$ has got the highest prevalence (58.87\%) and the lowest was at farm D (36.9\%) (Table 1). In this study, all the attendants practice hand milking and their knowledge about mastitis were only on clinical mastitis; none of them have awareness about subclinical mastitis. Out of 384 each quarter examined, $196(50.78 \%)$ and $19(4.95 \%)$ quarter of right front, $186(48.43 \%)$ and $36(9.37 \%)$ quarter of right hind, $179(46.61 \%)$ and $21(5.47 \%)$ quarter of left front and $170(44.27 \%)$ and $34(8.85 \%)$ quarter of left hind were CMT positive and blind in each quarter, respectively (Table 2).

Among 384 cows tested, where 170 of them belonged to the age group of 2 to 4 years, which 126 cows $(74.12 \%)$ had 290 infected quarters (42.64\%), 185 of them belongs to the age group of $4-8$ years, which 150 cows (81.08\%) had 378 infected quarters $(24.6 \%)$ and 29 of them belongs to the age groups of greater than 8 years, which 24 cows (82.75\%) had 62 infected quarters (53.44\%) (Table $3)$. Results of positive CMT realized on quarters showed that 730 out of $1536(47.52 \%)$ quarters were reached with variable degree of attack with subclinical mastitis. The degree was related to the CMT score as represented in Table 4. It was found that 177 out of the totally 1536 quarters (11.52\%) showed degree (+++), 238 ones $(15.49 \%)$ showed degree $(++), 315$ ones $(20.51 \%)$ showed degree $(+)$ and the rest 696 (45.32\%) showed negative (-).

Table 1: Quarter-wise prevalence of subclinical mastitis detected by CMT in cross- bred dairy cows in the farm.

\begin{tabular}{|c|c|c|c|c|c|}
\hline Study Farm & Total Quarters Examined & CMT Positive & CMT Negative & Blind Teats & CMT Positive (\%) Within Farm \\
\hline A & 84 & 31 & 50 & 3 & 36.9 \\
\hline B & 104 & 44 & 53 & 7 & 44.23 \\
\hline C & 96 & 55 & 36 & 5 & 57.29 \\
\hline D & 148 & 56 & 83 & 7 & 37.83 \\
\hline E & 240 & 121 & 99 & 20 & 50.41 \\
\hline F & 160 & 72 & 83 & 5 & 45 \\
\hline G & 252 & 87 & 94 & 23 & 42.82 \\
\hline H & 204 & 746 & 70 & 32 & 58.87 \\
\hline I & 248 & 47.52 & 45.31 & 7.16 & 47.52 \\
\hline
\end{tabular}

Table 2: Quarter-wise prevalence of subclinical mastitis using CMT test in cross-bred cows.

\begin{tabular}{|c|c|c|c|c|c|}
\hline Quarter & No. of examined & Blind & CMT Positive & Blind & Prevalence (\%) \\
\hline Right Front & 384 & 19 & 195 & 4.95 & 50.78 \\
\hline Right Hind & 384 & 36 & 186 & 9.37 & 48.43 \\
\hline Left Front & 384 & 21 & 179 & 5.47 & 46.61 \\
\hline Left Hind & 384 & 34 & 170 & 8.85 & 44.27 \\
\hline Total & 1536 & 110 & 730 & 7.16 & 47.52 \\
\hline
\end{tabular}

Table 3: Prevalence of mastitis in milking cows as influenced by age, lactation stage and parity.

\begin{tabular}{|c|c|c|c|c|c|}
\hline Risk factors & No. Animals Examined & No. of CMT Test Positive & Prevalence (\%) & $\mathbf{X}^{\mathbf{2}}$ & p- value \\
\hline Age (year) & & & & \\
\hline $2-4$ & 170 & 126 & 74.12 & \\
\hline $4-8$ & 185 & 150 & 81.08 & 2.9 & 0.234 \\
\hline
\end{tabular}




\begin{tabular}{|c|c|c|c|c|c|}
\hline$>8$ & 29 & 24 & 82.76 & & \\
\hline Total & 384 & 300 & 78.12 & & \\
\hline \multicolumn{6}{|c|}{ Stage of Lactation } \\
\hline$<3$ month & 129 & 91 & 70.05 & & \\
\hline 3-7 month & 131 & 109 & 83.21 & 6.78 & 0.034 \\
\hline$>7$ months & 124 & 100 & 80.65 & & \\
\hline Total & 384 & 300 & 78.12 & & \\
\hline \multicolumn{6}{|l|}{ Parity } \\
\hline $1-3$ & 258 & 214 & 82.95 & 12.50 & 0.002 \\
\hline $3-6$ & 123 & 83 & 67.48 & & \\
\hline$>6$ & 3 & 3 & 100 & & \\
\hline Total & 384 & 300 & 100 & & \\
\hline
\end{tabular}

Table 4: Relation between subclinical mastitis and degree of quarter attacked using CMT Quarter-wise.

\begin{tabular}{|c|c|c|c|c|c|c|}
\hline Degree & Right Front (\%) & Right Hind (\%) & Left Front (\%) & Left Hind (\%) & Total & Total Prevalence (\%) \\
\hline- & $170(24.42)$ & $162(23.28)$ & $184(26.44)$ & $180(25.86)$ & 696 & 45.31 \\
\hline+ & $76(24.12)$ & $74(23.49)$ & $79(25.07)$ & $86(27.3)$ & 315 & 20.52 \\
\hline++ & $61(25.63)$ & $64(26.89)$ & $63(26.47)$ & $50(21)$ & 238 & 15.49 \\
\hline+++ & $58(32.77)$ & $48(27.12)$ & $37(20.9)$ & $34(19.2)$ & 177 & 11.52 \\
\hline B & $19(17.27)$ & $36(32.72)$ & $21(19.09)$ & $34(30.9)$ & 110 & 7.16 \\
\hline Total & 384 & 384 & 384 & 384 & 1536 & 100 \\
\hline
\end{tabular}

Note: Negative (-), Weak positive (+), Distinct positive (++), Strong positive (+++), Blind (B).

\section{Discussion}

Out of 1536 quarters, 110 quarters examined for mastitis by California Mastitis Test (CMT) in cross-bred cows, (7.16\%) are blind of which right hind quarter $36(9.37 \%)$ was most affected and left hind quarter was more affected $34(8.85 \%)$ than both front quarters. This may be due to high production potential and easy to contamination by faeces and lack of screening tests and treatment of subclinical mastitis and inadequate follow-up of clinical and chronic cases. The relative high prevalence of mastitis in left right front $(50.78 \%)$ in this study agreed with the finding of others [21]. This may be due to ease of first grasping by milker's hand and easy for contamination. But the right hind (48.4\%) was not agreed and this may be due to greater contamination with feaces, urine and uterine discharge during delivery. The high occurrence of mastitisinduced blind mammary quarters, which has a direct influence on milk production with a subsequent impact on food security, signifies the importance of the problem.

Several authors reported an increase in mastitis frequency with age [22]. The present result was agreed in agreement with those reported by these authors as older cows ( $>8$ years) were more affected $(82.76 \%)$ than adult (4-8 years) cows $(81.08 \%)$ and younger (2-4 years) cows $(74.12 \%)$. This could be due to older cows have largest teats and more relaxed sphincter muscle which increase the accessibility of infectious agent in the cow's udder. If measurements taken at cow level with ignoring quarters level, serious underestimation of treatment effects in such affected quarters. Additionally, transmission of intra mammary infection occurs not only among cows but also among quarters within a cow [8]. The $47.52 \%$ prevalence of subclinical mastitis reported in this work was, relatively higher than previous studies in Ethiopia. $[9,23]$ reported $34.3 \%, 38.2 \%$ and $34.4 \%$, respectively and in the Chaffa valley in Northern Ethiopia 38.6\% [24] and in Debre Zeit in central Ethiopia (39.5\%) and less than the report in Tanzania (90.3\%) [7]; however, it is comparable with the report by [25] ( 47.5\%) in Modjjo farms in central Ethiopia, However, in two of the study sites in the present study a lower prevalence $(36.9 \%$ and $37.8 \%)$ were found.

These differences may be due to the generally greater experience in dairying, the potential effects of levels of milking hygiene, floor hygiene, herd size and cleanliness, and the application of sanitary measures such as post-milking teat dipping in these farms [26]. Stage of lactation and parity affect mastitis prevalence significantly $(p<0.05)$ which agreed with the findings of [27]. Cows with many calves $(>6)$ were at the highest risk $(100 \%)$ than those with fewer (3) calves (82.95\%) and moderate (3-6) calves (67.47\%). This could be associated with the possibility of exposure to infectious agents with increased number of parities. Subclinical mastitis prevalence was higher in late lactation (80.65 \%) and lower in early lactation $(70.54 \%)$ and highest in mid lactation $(83.21 \%)$. This could be due to presence of dry cow therapy regime could among the major factor contributing to low prevalence at early lactation.

The relationship between occurrence of mastitis and quantity of milk production was found not significant $(\mathrm{p}=0.584)$. This could be due to equal chance of contaminated environment. The rate of new intra-mammary infections is significantly high in the dry period than during lactation period and the greatest increase in susceptibility during the first 3 weeks of the dry period in which the new infection rate is higher than during the preceding lactation and the second period of increased susceptibility occurs 
just prior to calving and in the immediate postpartum period. In contrast [28] reported the risk of the infection increases when the milk production increase and the animal being very susceptible to the disease compared to their health and general lower yield herd. Most of the owners had poorly managed their farms because they didn't know the basic of farm production management and, they have not consulted professionals to help them on managing their farms.

This resulted in a poor performance of dairy production. Moreover, practical experience of mastitis control has confirmed the importance of the stand structures, ventilation, milking machine, management practices, milking technique and hygiene on udder health [29]. Most of the owners controlled mastitis by treating the clinical cases. Animals with chronic mastitis were sold off, slaughtered or were treated further with advice from a veterinarian. Good management practices such as milkers' hygiene, sanitization of milking machine and udder, healthy environment as well as dry off treatment and controlling other predisposing diseases should be considered among the major prophylactic measures to minimize the occurrence of the disease. Unfortunately, most infections are not detected until they become clinical, and by then extensive and costly damage can result. It was concluded the CMT can be used to monitor udder health trends over time.

In conclusion, bovine mastitis is described as one of the major constraints and most costly diseases in dairy production that limit enhanced milk production efficiency in many dairy herds despite the amount of knowledge available on the subject. It is a complicated problem associated with almost every conceivable factor of management and the environment. Some of the risk factors responsible for the high prevalence have been described including among others poor hygiene, management practices as well as cow factors. The major constraints to mastitis control included high treatment costs, insufficient or lack of veterinary services, difficulty in diagnosing the disease, low income, and poor hygiene and lack of equipment for controlling the disease. Effective control requires understanding of the farming system, the constraints that limit milk production efficiency and the risk factors under each farming system and different farm circumstances and adoption of possible and affordable options for control.

\section{Acknowledgement}

The authors are very grateful to the dairy farm owners and laboratory staff who gave their time to this research. All contributions and supports are gratefully acknowledged.

\section{References}

1. Yohannes A (2003) Clinical and sub-clinical mastitis in primiparous dairy heifers in Jordan. MSc Thesis. Faculty of Agricultural technology, Al-Salt University College, Al-salt, Jordan.

2. Smith BP (1996) Large Animal Internal Medicine: Diseases of Horses, Cattle, Sheep, and Goats. In Smith BP (Eds.). ( $2^{\text {nd }}$ edn.), Mosby-year book, USA, 11: 1177-1188.

3. Harmon RJ (1994) Physiology of mastitis and factors affecting somatic cell counts. J Dai Sci 77(7): 2103-2012.
4. Philpot WN, Stephen C, Nickerson (1999) In mastitis counter attack a strategy to combat mastitis. Pub-lished by Westphalia p. 60-65.

5. Mulei CM (1999) Teat lesions and their relationship to intra mammary infections on small-scale dairy farms in Kiambu district in Kenya. J South Afric Vet Assoc 70(4): 156-157.

6. Mungube EO (2001) Management and economics of dairy cow mastitis in the urban and peri-urban areas of Addis Ababa (Addis Ababa milkshed). MSc Dissertation. Freie Universitat Berlin, Germany, and Faculty of Veterinary Medicine, Addis Ababa University, Ethiopia.

7. Kivaria FM, Noorhuizen JP, Kapaga AM (2004) Risk indicators associated with subclinical mastitis in smallholder dairy cows in Tanzania. Trop Anim Helth and Prod 36(6): 581-592.

8. Lemma M, Kassa T, Tegegene A (2001) Clinically manifested major health problems of crossbred dairy herds in urban and periurban production systems in the central high lands of Ethiopia. Trop Anim Hlth and Prod 33(2): 85-89.

9. Workineh S, Bayleyegne M, Mekonnen H, Potgieter LND (2002) Prevalence and etiology of mastitis in cows from two major Ethiopian dairies. Trop Anim Hlth and Prod 34(1): 19-25.

10. Kerro 0, Tareke F (2003) Bovine mastitis in selected areas of Southern Ethiopia. J Trop Anim Helth and Prod 35(3): 197-205.

11. Mungube EO, Tenhagen BA, Regassa F, Kyule MN, Shiferaw Y, et al. (2005) Reduced Milk Production in Udder Quarters with Subclinical Mastitis and Associated Economic Losses in Crossbred Dairy Cows in Ethiopia. Trop Anim Helth and Prod 37(6): 1573-7438.

12. Miller GY, Barlet PC, Lance SE Anderson J, Heider LE (1993) Cost of clinical mastitis and mastitis pre-vention in dairy herds. J Amer Vet Med Assoc 202(8): 1230-1236.

13. Byarugaba DK, Nakavuma JL, Vaarst M, Laker C (2008) Mastitis occurrence and constraints to mastitis control in smallholder dairy farming systems in Uganda.

14. Lafi SQ Rawashdeh OFA, Erefe KI, Hailat NQ (1994) Incidence of clinical mastitis and prevalence of subclinical udder infections in Jordanian dairy cattle. Prev Vet Med 18(2): 89-98.

15. Tolla T (1996) Bovine Mastitis in Indigenous Zebu and Boran Holstein Crosses in Southern Wollo. DVM The-sis, Debre zeit: Faculty of Veterinary Medicine, Addis Ababa University: Ethiopia p. 25-27.

16. NMSA (2007) National metrology service agency. Addis Ababa, Ethiopia.

17. CSA (2008) Central statistical agency. Federal democratic republic of Ethiopia. Agricultural sample survey 2008/2009 (2001 E.c). Report on livestock and livestock characteristics, statistical bulletin 446: 39 .

18. Thrusfield M (2005) Veterinary Epidemiology. In Thrusfield M (Eds.), ( $2^{\text {nd }}$ edn.). (Black well science Ltd., London) pp. 182-198.

19. NMC (1990) Microbiological procedures for the diagnosis of bovine udder infection, ( $3^{\text {rd }}$ edn.), NMC Arlington p. 1-15.

20. Quinn PJ, Carter ME, Markey BK, Carter GR (1999) Clinical Veterinary Microbiology. In Quinn PJ, Carter ME, Markey BK, Carter GR (Eds.). Mosby International Limited, London, UK.

21. Shirmeko G (1996) Prevalence and Etiology of Subclinical Mastitis in Frisian-Indigenous Zebu Breeds of Dairy Cows in and around Bahir Dar. MSc Thesis, Faculty of Veterinary medicine, Addis Ababa University, Ethiopia.

22. Almaw G, Zerihun A, Asfaw Y (2008) Bovine mastitis and its association with selected risk factors in smallholder dairy farms in and around Bahir Dar, Ethiopia. Tropical Animal Health and Production 40(6): 427-432.

23. Fekadu K (1995) Survey on the prevalence of bovine mastitis and the predominant causative agents in Chaf-fa valley. Proceedings of the $9^{\text {th }}$ Conference of Ethiopian. 
24. Abaineh D, Yirgalem G, Sintayehu A (2002) Treatment dose estimation trial of Persicaria senegalense herb against sub-clinical mastitis. J Ethiop Vet Assoc 4: 13-22.

25. Fröberg S, Gratte E, Svennersten Sjaunja K, I Olsson, C Berg, et al. (2008) Effect of suckling ('restricted suckling') on dairy cows' udder health and milk letdown and their calves' weight gain, feed intake and behaviour. Applied Animal Behav-iour Science 113(1-3): 1-14.

26. Biffa D, Etana D, Fekadu B (2005) Prevalence and Risk Factors of Mastitis in Lactating Dairy Cows in Southern Ethiopia. Intern. J Appl Res Vet Med 3(3): 189-197.

ISSN: 2574-1241

DOI: $10.26717 / B J S T R .2019 .12 .002318$

Fufa Abunna. Biomed J Sci \& Tech Res

(C) This work is licensed under Creative

Submission Link: https://biomedres.us/submit-manuscript.php
27. Gröhn YT (2000) Milk yield and disease: towards optimizing dairy health and management decisions. Bovine practitioner 34(1): 32-40.

28. Abdullah SA (2002) Milk production and management of its schemes in Sudan. $4^{\text {th }}$ Chapter p. 59- 62.

29. Hillerton JE, Berry EA (2005) Treating mastitis in the cow--a tradition or an archaism. J Appl Microbiol 98(6): 1250-1255. 